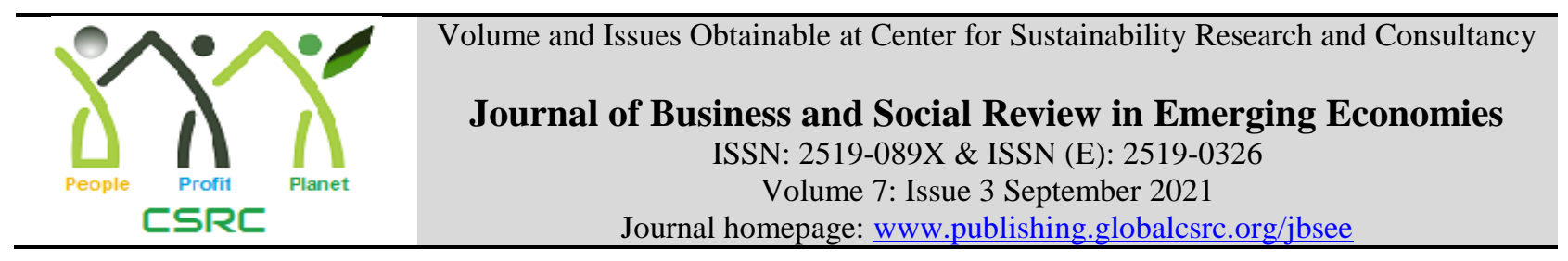

\title{
Health Policies Formulation in Pakistan: An Analysis
}

Zeb-un-Nisa, Government College University, Faisalabad, Pakistan

Muhammad Ashraf Nadeem, International Relations, Department of International Relations, Government College University, Faisalabad, Pakistan

*Ghulam Mustafa, Department of International Relations, Government College University, Faisalabad, Pakistan

*Corresponding author's email: ghulammustafa@gcuf.edu.pk

\begin{tabular}{l}
\hline ARTICLEDETAILS \\
\hline History \\
Revised format: Aug 2021 \\
Available Online: Sep 2021
\end{tabular}

Keywords

Health Policy Formulation,

Policy Process, Policy Implementation/execution.

JEL Classification II, III

\begin{abstract}
Objective: A reviewing study of the health policy planning and formulation was initiated which explored the procedure of formulation of health policy and its implementation in Pakistan. The purpose of the study is to learn the procedure of health policy formulation and its implementation and to observe the issues in health system in Pakistan.
\end{abstract}

Methodology: This study on health policy formulation was exploratory in nature. The research design was qualitative. The data was collected through secondary sources which includes research articles published in various journals and available on online sites. Moreover, data was also collected through books written on public policy by some foreign and local authors. Findings: The findings indicates that the planning and policy formation of the health sector in Pakistan is capable at the preparation level but not at the execution level. Implications: This paper recommends overcoming the health-related problems in Pakistan through formulation and implementation of sound, assertive and credible policies.

(O2021The authors, under a Creative Commons AttributionNonCommercial 4.0

Recommended citation: Nisa, Z., Nadeem, M. A. and Mustafa, G. (2021). Health Policies Formulation in Pakistan: An Analysis. Journal of Business and Social Review in Emerging Economies, 7(3), 537-546.

\section{Introduction}

To define the human resources, health plays a main role. Good health increases the productivity and performance of the working forces and resulted in human prosperity and economic progress. Each nation has a structure of health services along with its systems of farming, education, transportation, and several other social measures. At the end of the 19th century, the concept had arisen in Europe that healthcare services were a civic responsibility (Bjorkman, 1986). Pakistan's health care system comprised of public as well as private sectors. According to the constitution of the country, basically, health is the responsibility of the provincial government, excluding the federally governed areas. The supply of health care has historically been regulated collectively by federal and provincial governments with districts largely responsible for the execution (Home 
Office, 2020). By 2018, the number of public sector hospitals has risen to 1279, Basic Health Units (BHUs) to 5527, Rural Health Centers (RHCs) to 686, and dispensaries to 5671. Along with 220829 licensed doctors, 22595 registered dentists, and 108474 registered nurses, these hospitals carry the current ratio of one doctor to 963 patients, 9413 people to one dentist, and 1608 people to one hospital bed (Finance Division, 2019). In 2019, the Pakistan Bureau of Statistics has published a study in which a total of 1279 hospitals were reported; 5671 clinics, $747 \mathrm{MCH}$ (Maternal and Child Health) providers, 441 tuberculosis centers, 686 rural healthcare facilities, 263 sub-health clinics, and 5,264 basic health centers throughout Pakistan, with a cumulative value of 132227 beds (Pakistan Bureau of Statistics, 2019). As of 2019, the Pakistan Economic Survey 2019-20 reported the total range of approved healthcare staff: 233261 physicians, 24930 dentists, 112123 nurses, 41810 midwives, 20565 Lady Health Visitors (Finance Division, 2020).

\section{Literature Review}

Health policies of the states are considered as the strategies, actions and resolutions which are necessary to attain specific healthcare goals within the state (Asim, 2019). Different researchers have defined the "health policy" in different ways. (Bjorkman, 1986) explains that "Policy is not what people (or a government) say will be done, but rather what has been done". Furthermore, a policy is divided by him into two kinds; the first one is the normative policy that proclaims and evaluates the desired goals and objectives for the future and the second one is the empirical policy that observes the record of the past and practices of the present.

According to World Health Organization (WHO), a pure and clear-cut health strategy can achieve various objectives: It explains a healthful image for the country's upcoming years; it draws significances, dominances, and the predictable role of diverse social clusters and, it makes possible the harmony, treaties, and transform the masses (Asim, 2019).

\section{Research Methodology}

This study on health policy formulation was exploratory in nature. The research design was qualitative. The data was collected through secondary sources which includes research articles published in various journals and available on online sites. Moreover, data was also collected through books written on public policy by some foreign and local authors.

\section{Public Health (Pre-Independence)}

It is possible to identify the roots of health planning in Pakistan by pointing out the early public health initiatives carried out by the officials in the sub-continent long before the creation of the country. The British introduced the public sector health services for their employees and metropolitan areas. Before this, the traditional medication methods were in practice, which are still being exercised.

A Superintendent General for vaccination was nominated after Jenner's launch of the vaccine against smallpox, and a law to grant vaccination power was passed by the Government of India in 1880. Maybe, it was the government's initial assurance that eventually led to the elimination of smallpox (Lashari, 2004). In April 1896, with the incorporation of the Bengal Medical Service, the Bombay Medical Service and the Madras Medical Service, the Indian Medical Service of the East India Company gained an all Indian characteristic. The medical services introduced by the British obliged their purposes, i.e. looking after of health of their soldiers and European colonists, instead of the health requirements of the common people (Bajpai \& Saraya, 2013). The Epidemic Diseases Act 1897, The Vaccination Act 1880, and the Births and Deaths Registration Act (1873) were additional measures. In 1939, the Madras Public Health Law was passed, which was the $1^{\text {st }}$ of its sort in India (Park, 2007). Four significant milestones in the development of health planning and decision making in the Subcontinent have been described by the Bhore Committee: 
i. In 1859, Nomination of Royal Commission to investigate the health of the military in India.

ii. The report regarding Plague Commission in 1904 after the epidemic of plague in 1896.

iii. In 1919, reformation presented by the Government of India Act, 1919.

iv. In 1935: Reformation announced by the Government of India Act, 1935 (Bhore, 1946).

Public Health-Post Independence

Along with political patterns, the healthcare system of a nation is affected by its socio-economic growth. British colonial rule was primarily responsible for the upgrading of healthcare facilities in Pakistan. And after independence in 1947, this influence remained continued. The development of health planning in Pakistan can be categorized by various achievements which include:

\section{Bhore Committee 1943-1946 (A Historical Landmark)}

In 1943, under the presidency of Sir Joseph Bhore, a retired Indian associate of the Indian Civil Service then former Health Minister, the Health Survey and Development Committee was set up to undertake a comprehensive review of the prevalent fields of medical treatment including public health (Kavadi, 2019). It was noted by the Bhore Report about rural healthcare, that dynamic patronage of the public is required by establishing health committees in each village, motivating the local participation for the improvement of sanitation and hygiene conditions, by controlling infectious diseases and further purposes. A broad plan of health education, for all sectors of the community, is also recommended in order to promote the development of public patronage (Bhore, 1946).

\section{National Plans from 1955 to 2020 and Health Policy}

The five-year plans stay on at the forefront of Pakistan's economic forecasting. As far as health is concerned, the nation does not have an emphatic health program. However moderate five-year plans drawn up by the planning Board which made choices for the health sector of the region.

\section{Alma Ata Declaration 1978}

A conference was organized at Alma Atta, in Kazakhstan (former the Soviet Union) on 12th of September 1978 by UNICEF and WHO jointly.

Pakistan was one of the first signatories of the Alma-Ata Declaration 1978 (Ronis \& Nishtar, 2007). The eradication of malaria and control of various other diseases was at the top priority of WHO during the 1950s and 1960s. U.S government mainly supported the commitment of the WHO for malaria eradication and initiated in the mid of 1950s. At that time, the Soviets were not taking part in the work of WHO as they had withdrawn from 1949 but join back in 1957 (Litsios, 2002). The health paradigm was shifted to primary healthcare after the Alma Ata Declaration. For this purpose, the government made various changes in the infrastructure by providing Primary Health Care (PHC) services. As a result, the PHC services were provided to $70 \%$ of the rural population with health facilities within five-kilometer and to the whole urban population (Kurji, Premani, \& Mithani, 2016).

\section{National Health Policies Planning and Formulation}

A guideline for the provincial and federal governments is provided in the health policy of Pakistan to encourage innovative ideas in the health sector and to transform the previously prevailing health sector of Pakistan (Asim, 2019). During the 1970s the efforts were made for the establishment of an internal health program. In 1972, the Federal Ministry declared the "Peoples Health Scheme" entitled for an extensive increase in health expenditures (Khattak, 1996). A serious discussion and consideration about the formulation of health policy was started during the decade of 1970s. But, attempts to develop a national health policy were not started until 
1988. It was after a prolonged period of military rule. A health policy was offered in 1990 after broad discussions. This policy described its goals to be achieved during the ten years (Lashari, 2004). National policies are included the Peoples Health Scheme of 1972, the National Health Policies of 1990, 1997, 2001, and 2009, Vision 2030, and National Health Vision 2016-2025.

\section{The National Health Policy 1990}

High concern for health was presented in the first National Health Policy by enhancing the health expenses up to $5 \%$ of GNI. For the improvement of health, family planning and provision of clean water were given consideration (Hassan, Mahmood, \& Bukhsh, 2017). The focus of this policy was on the provision of health services in schools, malaria control programs, nutrition programs, family planning, control of infectious diseases (e.g. infective hepatitis and tuberculosis), clean drinking water, and sanitation for public health and health promotion (Ronis \& Nishtar, 2007).

\section{Social Action Program}

The government of Pakistan initiated a vast Social Action Program in 1993-1994, with the help of the World Bank as well as other donors. At the cost of Rs.106.4 billion, the initial stage was accomplished. While, with an approximated cost of Rs.498 billion, SAP-II (1997-2012) was launched. The focus of SAP was on primary health, development of primary education, population welfare, sanitation, and rural water supply (Lashari, 2004).

\section{The National Health Policy 1997}

The Social Action Program (SAP-1) was previously executed and SAP-II was expected to be adopted at the same time of initiation of the National Health Policy 1997. Thus, the foremost emphasis of the government and global organizations was towards the health issues at the same time.

In 1997, the second National Health policy was articulated. The concept "Health for All" (HFA) was its foundation. Road traffic accidents, HIV/AIDS, cancer, tuberculosis, violence, mental health, and diabetes were given attention (Hassan, Mahmood, \& Bukhsh, 2017). Under priority health programs, health education, and health promotion were given obvious place, and noninfectious diseases i.e. diabetes, cancer, and cardiovascular disease were highlighted for prevention and control measures (Ministry of Health, 1997). Under the District Health Government Initiatives, decentralization of the health (later on it was uncontrolled). Initiating of eradication of poliomyelitis (led by WHO), social action programs (led by the World Bank) and initiation of Lady Health Worker Program. Backing for vertical disease prevention and control programs (federally directed) with global share (Stop TB, Roll Back Malaria, GAVI Alliance, Global Fund to Fight Tuberculosis, AIDS, and Malaria) (Nishtar, et al., 2013).

$+$

\section{Millennium Development Goals (MDGs)}

A Millennium Declaration was executed in 2000 by the General Assembly of United Nations by introducing an international alliance of countries and development allies shown commitment to eight voluntary development objectives with the aim of empowers and keeps track of societal indicators (Khaliq \& Ahmad, April 2018). Succeeding its participation in the MDG in 2002, Pakistan's Government became the forefront in establishing a national private and public partnership with the aim to achieve the MDGs. The collaboration was between the private donors both from abroad and Pakistan, civil society organizations and private donors, and United Nations Development Program (UNDP). They performed their work in 53 districts of the country in the field of health and education (Kurji, Premani, \& Mithani, 2016). The MDGs were based on 48 indicators, 18 targets and 8 goals. 


\section{The National Health Policy 2001}

The National Health Policy's Preface stated that "the new health policy provides an overall national vision for the Health Sector based on Health for All approach" (Ministry of Health, 2001).

\section{Vision 2030: Pakistan in $21^{\text {st }}$ Century}

The Vision 2030 was presented in August 2007 by the Planning Commission of Pakistan to meet the needs of the $21^{\text {st }}$ century.

The VISION 2030 envisions an industrialized, developed, just, and prosperous Pakistan through sustainable and speedy growth in a resource restrained economy by organizing knowledge inputs. The Millennium Development Goals - MDGs 2015 have fixed the Human Development targets (Planning Commission, 2005). The provincial health departments contextualize their policy frameworks under the National Health Vision 2016-2015 with an opinion to reach universal health coverage. Helpful provincial commandments have been presented in this regard comprising Sindh Occupation Protection and Health Act 2017, the Punjab Hepatitis Act 2018, the Khyber Pakhtunkhwa Mental Health Act 2017, the Khyber Pakhtunkhwa Public Health Act (response and surveillance) 2017, and the Baluchistan Juvenile Smoking Act 2018 (Ministry of Planning Development and Reforms, 2019)

\section{The National Health Policy 2009}

The vision of the National Health Policy 2009 clearly indicates that a health system "is efficient, equitable \& effective to ensure acceptable, accessible \& affordable health services. It will support people and communities to improve their health status while it will focus on addressing social inequities and inequities in health and is fair, responsive and pro-poor, thereby contributing to poverty reduction" (Ministry of Health, 2009). The policy draft was drawn up in response to a country-wide discussion, but it could not be enforced due to the 18th Amendment. All the provinces have developed their own strategies as a substitute for it. The health system framework of WHO of six building blocks was followed by all provinces to develop their strategies (World Health Organization, 2020). All districts, provincial and federal governments are assigned very flawless roles and duties but in practical positions, they are overlapping. The federal government is responsible for the provision of technical backstopping, policymaking, coordination with various allies inside and outside the country, funding for health care, and control of the transmittable disease (Ministry of Health, 2009).

\section{$18^{\text {th }}$ Amendment and Devolution of Power and Responsibility}

On 30 June 2011, the Ministry of Health was decentralized to the provinces by the Federal Government under the 18th amendment. Though in April 2013, it was reinstalled again but most of the responsibilities and programs of the Ministry of Health are assigned to the provincial health department (Hassan, Mahmood, \& Bukhsh, 2017). The ministry of health and the concurrent lists was abolished in 2001 after the promulgation of the 18th amendment. Different federal ministries were assigned the residual health allied duties included in the Federal Legislative Lists (Part I \& II). In May 2013, the Cabinet agreed to establish a "National Health Services, Regulations and Coordination Division" (NHSR\&C) for the management of the health functions in harmonize and effective way (Ministry of National Health Services, 2018). The formation of the New Ministry was with the directive of provision of mutual strategic vision, to attain Universal Health Coverage (UHC) through assessable, effective, affordable, and reliable health facilities programs, to coordinate the population welfare and public health at the international and national level, to deliver an oversight to regulatory bodies, to accomplish worldwide agreements and requirements, to legalize medical education and profession and to impose drug regulations (Ministry of National Health Services, 2018). After the decentralization of the health system in 2012, the provinces of Pakistan keep following similar procedures using the slight capability to produce evidence and include it into health policy as before 2012 (Haq, 
Hafeez, Zafar, \& Ghaffar, 2017). Under the 18th constitutional amendment, the latest transition of power from the federal government to the provinces in the country has formed the chance and hopes to institutionalize reform (Nishtar, et al., 2013). A challenging opportunity was provided by the political devolution in the country for the health care system to address the problems related to planning health care delivery structures, systems, services, and programs. This is of greater importance because that the objectives of health-related MDGs were not entirely accomplished and to meet the much more ambitious objectives of the Sustainable Development Goals more determinations are needed (Government of Pakistan, 2016).

\section{National Health Vision 2016-2025}

The description of the National Health vision is constructed on the eight thematic pillars. These pillars will pave a way for the safety, coverage, quality, and confirm access which is necessary for the achievement of the definite objectives of the health system; responsiveness, improved health, efficiency, and social protection. These eight pillars are; Health Service Delivery, Health Financing, Human Resource for Health, Governance, Health Information System, Cross-sectoral linkages, Essential Medicines \& Technology, and Global Health Responsibilities (Government of Pakistan, 2016). The document further specified that Treaties like the Global Health Security Agenda (GHSA) and International Health Regulations 2005 (IHR) require some core capability that has not yet been properly developed at the provincial and federal levels.

\section{Action Plan: National Health Services, Regulation and Coordination Division 2019-2023}

To transform the health sector of Pakistan, the prioritized strategic actions of the new government were sets out by the Action Plan by addressing the health sector reforms, challenges, and improvement of the health outcomes of the people of the country. This action plan will support the progress for the achievement of Sustainable Development Goals (SDGs), International Health Regulations (IHR), the Universal Health Coverage (UHC), and enlarge the existing sub-sectoral and sectoral plan and strategies in the country (Ministry of National Health Services, 2018). For efficient and quick response during disease outbreaks, a national Integrated Disease Surveillance System and Response (IDSR) system will be set up.

\section{New Initiatives 2018-2020 \\ Sehat Sahulat Program (SSP)}

The National Health Program of the Prime Minister commonly known as the "Sehat Sahulat Program" (SSP) helped individuals with disabilities (inhabitants of Punjab, Islamabad Gilgit Baltistan \& Azad Jammu and Kashmir), transgender individuals (around Pakistan), and people who are living under the poverty line. The State Life Insurance Corporation of Pakistan is executing the Sehat Sahulat Program in the country (SSP).

To provide health insurance to needy persons, the "Sehat Sahulat Program" (SSP) a new universal health coverage program, was initiated in 2019. Reforms in the health sector including a resilient inter-provincial information sharing apparatus and a central cohesive surveillance system for diseases are in progress (Ministry of Planning Development and Reforms, 2019).

\section{Benefit Packages of Phase-I}

Every registered family would be insured up to Rs. 250,000/- annually for 7 priority care treatment and up to Rs.50,000/- annually for secondary care medication through Sehat Sahulat Program. Patients who have utilized their restrictions will be supplied with extra margins by Pakistan Bait-ul-Mal.

\section{Benefit Packages of Phase-II}

The assistance package of every registered family has been boosted up to Rs.600,000/- annually for 8 significant illnesses/diseases related treatment and up to Rs.120, 000/- annually for 
secondary care treatment in the second phase of the Sehat Sahulat Program (Finance Division, 2019).

The Economic Survey of the Government of Pakistan, which assessed the economic success of Pakistan during the fiscal year 2018-19, summarized in its chapter on health and nutrition; that there is a dire need to aggressively increase the health budget allocation by provincial and federal governments specifically development expenses for the provision of enlarged and improved quality health services throughout the country because the health sector in Pakistan is facing threatening challenges (Finance Division, 2019). Due to the indirect and direct effects of the COVID-19 pandemic, the challenges for the health system will be further worsened. A considerable health risk has posed by the pandemic for an already susceptible population of the country with an insufficient infrastructure of healthcare (Finance Division, 2019).

\section{Findings}

More than seventy-two years of history of Pakistan's health planning is striking by various initiatives in different periods. However, a lack of a consistent process is observed the whole time. The wanted level of health status has not been attained until the improvement of strong planning instruments. Socio-economic elements significantly affect health. Formally, health policy formulation in Pakistan is the duty of the Planning Commission and the Federal Ministry of Health (currently the Ministry of National Health Services, Regulations and Coordination) whereas planning and execution of the policies is the duty of the provinces. Under a freshly decentralized setup, the responsibilities are further distributed to the districts. The procedure of the policy-making is performed in the Ministry of Health through a fixed hierarchy of steps. Main problems are as given below:

The nation inherited a state of insufficient medical services, nutrition deficiencies, unsanitary environmental situations, and poor maternal care at the time of independence. Subsequently, the growth of health facilities in response to health manpower has been critically sluggish. Due to which the health facilities in both rural and urban areas are insufficient.

The health issues of any country directly linked with the prevailing economic, social, and political systems which regulate the resources allocation outside or within the health sector. The health sector is encountering foremost challenges such as jobless doctors in spite of the severe shortage of capable health workers, shortage of rural health services, the "brain drain" of medical degree holders, pharmacological companies stirring themselves at the expenditure of common man, lack of drinking water and ample sewerage in rural and slums areas, medical degree holders incapable in performing their duties in the rural area and their excessive reliance on sophisticated technology.

The prime constraint of the weak health situation of the population in developing countries like Pakistan is extreme poverty. Without broken of the poverty cycle, the implementation of health sector reforms will be challenging.

The healthcare system of Pakistan is incompetent, insufficient, and expensive. It consists of inefficient and an underfunded public sector as well as an expensive, mixed, unregulated private sector. Such poor health conditions of the health sector can be credited to a variety of elements i.e. malnourishment, poverty, insufficient allocation for health, imbalanced access to health services, rapid population progression, and infant mortality. Input from both the public as well as private sectors will be important for the effectiveness, equity, and efficiency of the health sector (Akram \& Khan, 2007).

For the improvement and evaluation of the services provided at the primary and secondary level, a consistent information management system is not available. One of the causes of the 
deliverance of insufficient services is the shortage of medical technology and research at the national level.

Provided health plans are unhealthy and badly implemented. There are several reasons for low performance i.e. corruption, inadequate public health funding in the public sector, lack of accountability, and political interference.

The majority of people in Pakistan don't believe on government hospitals. They consider that neither appropriate health services are available in government hospitals nor the doctors in these hospitals look after the patients honestly. Therefore, they generally prefer private hospitals to improve maternal health and decrease child mortality.

In all four provinces, the non-salary expenses of Primary Health Care (PHC) facilities indicate that due to the dearth of funds the PHC is suffering.

According to the World Bank, the private sector is the main supplier in Pakistan with a $77 \%$ share of health expenditures (The World Bank, 1999). But such a gigantic shareholder is not integrated into public health planning which is a predicament of the health sector of the country. The inability of successive governments to implement the policy is a significant challenge in the country. Among these problems, the important issue is the governance issue. At the implementation stage, there are serious issues. Policies documents are prepared and well planned, but they failed mostly because of the lack of ineffective financing system, centralism, lack of training, and managerial in-capabilities.

One of the major problems is centralized implementation. The tiers of the federal government do not determine by the policy process. To conclude, a common misunderstanding is that policies are upright but actual problems exist at the stage of implementation of policies.

\section{Recommendations}

Health policies can be supported by education. Both adults and children can be trained that why clean water is important, why personal hygiene is important and what are the causes of the major diseases. The nutritional components can be advised to enhance the nutritional value, what foods can be generated on home-based farms and to preserve the maximum nutritional value how to cook it.

In Pakistan, there is strong consent that structural changes are needed in the health sector for a better effect on the population's health status.

The budget allocation for the health sector must be enhanced by the federal and all provincial governments, specifically development expenses as the health sector in the country is facing a lot of challenges.

The health policy's success rests in its implementation at all levels with the collaboration of private and public sector and backing of global development allies. For effective implementation of the health policy, cooperation between local and district governments, provincial health departments and ministry of health will be helpful.

The main focus of health policies is on curative Healthcare, i.e. laboratories, ambulances, a growing number of health services, and the latest types of equipment without evaluating how untrained medical practitioners for modern technologies will use them. Even though at the time of formulation of policies the ground realities, social dimensions, cultural and religious values are ignored and perception is gained from the success stories of developed countries without paying attention to economic differences. 
For the solution of a nationwide shortage of accurate health services, the budget allocation for the health sector should be increased significantly.

Numerous flaws are present in the formation, execution, and monitoring of health policies. Physical and financial targets may be achieved but functional aspects may linger on.

Governments subsidize health care services for their population in order to gain stronger, more educated, effective, and profitable human capitals. The full or particular part of the expenses of available health care facilities is paid by the public sector.

\section{Conclusion}

To conclude, the country has had various five-year plans, health reform commissions, and health planning documents. The health policy of Pakistan does not alter itself entirely into an evidencebased, dynamic, comprehensive, feasible, and rational policy. The nature of the policy is highly centralized. It is based on estimations rather than dependable data which determine that it lacks the essential footing for implementation. Henceforth, implementation is not the only issue but planning and formulation as well. The planning and formulation are achievable and not costeffective so, the implementation turns out to be further difficult. With the empowerment of the federal system in the country, the health system is in the procedure of regeneration. Although, opportunities, as well as challenges, have been created by the 18th constitutional amendment and improvement in the governing system is the imaginable mode for the improvement of the health sector. Seventy-two years history of health planning in Pakistan is labeled by numerous initiatives at various times but it always demanded a reliable and articulate procedure. The cherished level of health position has not been attained despite the development of a solid planning mechanism. An in-depth examination is mandatory to probe cases of the failure.

\section{References}

Home Office.(2020). Country Policy and Information Note Pakistan: Medical and healthcare Provisions, Version 2.0. Assessed from https://assets.publishing.service.gov.uk/government/uploads/system/uploads/attachment_ data/file/924029/Pakistan_Medical_and_Healthcare_issues_-_CPIN.pdf on 25-10-2020.

Akram, M., \& Khan, F. J. (2007). Health Care Services and Government Spending in Pakistan (PIDE Working Papers). Islamabad: Pakistan Institute of Development Economics.

Asim, M. (2019). Health Policy of Pakistan and U.K: Differences in Enforcement. Assessed from https://www.academia.edu/39125187/Health_Policy_of_Pakistan_and_U_K_Differences _in_Enforcement on 27-05-2020.

Bajpai, V., \& Saraya, A. (2013). Development of Health Care Services in India . The National Medical Journal of India , 100-105.

Bhore, S. J. (1946). Report of the Health Survay and Development Committee: Survey. Delhi: Government of India Press.

Bjorkman, J. W. (1986). Health Policies and Human Capital: The Case of Pakistan. The Pakistan Development Review, 281-337.

Finance Division. (2019). Pakistan Economic Survey 2018-2019. Islamabad: assessed from: http://www.finance.gov.pk/survey_1819.html 04-05-2020.

Finance Division. (2020). Pakistan Economic Survey 2019-20. Islamabad: http://www.finance.gov.pk/survey_1920.html.

Government of Pakistan. (2016). National Health Vision Pakistan 2016-2025. assessed from https://extranet.who.int/countryplanningcycles/sites/default/files/planning_cycle_reposito ry/pakistan/national_health_vision_2016-25_30-08-2016.pdf on 25-05-2020.

Haq, Z., Hafeez, A., Zafar, S., \& Ghaffar, A. (2017). Dynamics of Evidence-informed Health Policy Making in Pakistan. Health Policy Plan, 1449-1456. 
Hassan, D. A., Mahmood, D. K., \& Bukhsh, D. H. (2017). Healthcare System Of Pakistan. International Journal of Advanced Research and Publications, 170-173.

Kavadi, S. N. (2019). John B Grant and Public Health in India. Indian Journal of Medical Ethics, DOI: https://doi.org/10.20529/IJME.2019.010.

Khaliq, F., \& Ahmad, W. (April 2018). State of Health Sector in Pakistan. Assessed from: https://www.sbp.org.pk/publications/staff-notes/State-of-Health-Sector-in-Pakistan-(0604-2018).pdf on 05-05-2020.

Khattak, F. H. (1996). Health economics and planning in Pakistan. Islamabad, Pakistan: Planning Commission.

Kurji, Z., Premani, Z. S., \& Mithani, Y. (2016). Analysis of the Health Care System of Pakistan: Lessons Learnt and Way Forward. J Ayub Med Coll Abbottabad., 601-4.

Lashari, D. (2004). Pakistan's National Health Policy: Quest For A Vision. Islamabad, Pakistan: The Network Publications,.

Litsios, S. (2002). The Long and Difficult Road to Alma-Ata: A Personal Reflection. International Journal of Health Services, 709-732.

Ministry of Health. (1997). National Health Policy 1997. Islamabad: Ministry of Health, Government of Pakistan.

Ministry of Health. (2001). National Health Policy. Islamabad: Ministry of Health, Government of Pakistan.

Ministry of Health. (2009). National Health Policy. Islamabad: Ministry of Health, Government of Pakistan.

Ministry of National Health Services, R. a. (2018). Action Plan - National Health Services, Regulations and Coordination Division 2019-2023 . Islamabad, Pakistan: HPSIU Ministry of National Health Services, Regulations and Coordination.

Ministry of Planning Development and Reforms. (2019). Pakistan's Implementation of the 2030 Agenda for Sustainable Development: Voluntary National Review. Isamabad, Pakistan: SDG Section, Ministry of Planning, Development and Reforms Government of Pakistan.

Nishtar, S., Boerma, T., Amjad, S., Alam, A. Y., Khalid, F., Haq, I. u., et al. (2013). Pakistan's Health System: Performance and Prospects After the 18th Constitutional Amendment. Published online by www.thelancet.com Vol 381, 2193-2206.

Pakistan Bureau of Statistics. (2019). Compendium on gender statistics of Pakistan 2019. Islamabad: Minitry of Planning, Development and Reform, Government of Pakistan.

Park, k. (2007). Park's Textbook of Preventive and Social Medicine. Jabalpur, India: M/S Banasidas Bhanot.

Planning Commission. (2005). Medium Term Development Framework 2005-2010. Islamabad, Pakistan: Assessed from: http://www.pc.gov.pk/mtdf.html on 15-05-2020.

Ronis, K. A., \& Nishtar, S. (2007). Community Health Promotion in Pakistan: A Policy Development Perspective. IUHPE - Promotion \& Education Vol. XIV, No. 2, 98-99.

The World Bank. (1999). World Report on Development: Knowledge for Development 1998/99. Washington, D.C., U.S.A.: The International Bank for Reconstruction and Development / THE WORLD BANK.

World Health Organization. (2020). Assessed from http://www.emro.who.int/pak/programmes/health-policy-governance-and-leadership.html on 15-05-2020. 